\title{
Elder Financial Abuse: An Evaluation Framework and Supporting Evidence
}

\author{
Bryan J. Kemp, PhD and Laura A. Mosqueda, MD
}

OBJECTIVES: To develop a valid and reliable framework for evaluating cases of alleged elder financial abuse.

DESIGN: Experienced experts in elder financial abuse rated a framework with eight elements.

SETTING: Professionals attending an advanced training course on elder abuse.

PARTICIPANTS: Deputy district attorneys $(\mathrm{n}=44)$, senior law enforcement detectives $(n=59)$, Adult Protective Service workers, and public guardians and victim advocates $(\mathrm{n}=56)$ who had a combined total of 1,985 years of experience and who had investigated a total of 3,225 cases (mean of 13.1 years and 21.2 cases) were included.

MEASUREMENTS: These experienced professionals were asked to rate how well an evaluative framework matched their experience with elder financial abuse using a 5-point rating scale ranging from very little to almost entirely.

RESULTS: The mean rating for the model was 4.4 out of 5 . About $90 \%$ of the sample rated it as almost entirely or very much matching their experience. There were no differences between professions. The reliability measure was 0.85 .

CONCLUSION: These results suggest a reliable and valid framework for evaluating cases of possible elder financial abuse. J Am Geriatr Soc 53:1123-1127, 2005.

Key words: financial abuse; assessment; framework

$\mathbf{F}$ inancial abuse is one of the more common forms of abuse perpetrated against older people. In a recent national study of elder financial abuse, ${ }^{1}$ it accounted for about $20 \%$ of all substantiated elder abuse perpetrated by others (after excluding self-neglect). It is also estimated that, for every known case of elder financial abuse, four to five go unreported. ${ }^{1}$ Rates may even be higher than this. One study $^{2}$ estimated that about $33 \%$ of one million cases of

From the Elder Abuse Forensic Center, University of California at Irvine College of Medicine, Irvine, California.

This research was partially supported by a grant from the Archstone Foundation.

Address correspondence to Bryan Kemp, PhD, 7601 E. Imperial Highway, 800 West Annex, Downey, CA 90242. E-mail: bkemp@uci.edu

DOI: $10.1111 / \mathrm{j} .1532-5415.2005 .53353 . \mathrm{x}$ elder abuse were financial. Other studies have reported similar rates and have concluded that financial abuse is among the top three forms of elder abuse. ${ }^{3}$ The effect of financial abuse on older people is devastating. In addition to robbing them of their economic resources, it often causes extreme emotional distress or depression, increased dependence on others, a change in residence, decreased resources for medicines and health care, and a diminished quality of life. It may therefore also lead to a shorter-thanexpected life expectancy. Moreover, other populations, such as adults with disabilities, are also subject to the same kind of abuse.

Perpetrators of elder abuse can be found outside the family, such as contractors, salesmen, attorneys, caregivers, insurance agents, clergy, accountants, bookkeepers, and friends, or they can be family members, who are usually motivated to gain a larger share of the assets for themselves. Because much abuse goes unreported, it is difficult to determine exact percentages of each type of abuser.

Financial abuse of older people is expected to increase in the future because of four main factors. First, the size of the older population is increasing at a rapid rate. In 1950, the 65 and older age group was approximately $8 \%$ of the population. Today, it is about $13 \%$ of the population, and when the "baby boomer" population reaches age 65 (beginning in 2011), the percentage will eventually increase to about $20 \%$ to $23 \%{ }^{4}$ Second, older persons also own a disproportionately large share of the wealth in the United States. A combination of property ownership, prolonged savings, investments, and inflation has resulted in many older people having a substantial net worth. ${ }^{5}$ Moreover, many older people have good credit, and this can be considered another valuable asset that others can take advantage of. Third, vulnerability to abuse increases with age because most mental, physical, and social problems also increase with age. For example, the prevalence of dementia is less than $1 \%$ in the under- 65 age group, but is $4 \%$ in the 65 and older group, $16 \%$ in the 75 and older group, and $30 \%$ in the 80 and older age group. ${ }^{6}$ The fourth reason elder financial abuse is increasing is that the variety, complexity, and creativeness of ways to take financial advantage of older people are also increasing. Today, there are scores of scams, misdeeds, and rip-offs designed to take advantage of vulnerable older people: being notified that one has won a foreign lottery but needs to pay the taxes or fees on it; 
being told that their house is in dire need of repair; or having a 90-year-old person sell stocks to buy an annuity that will not pay for 10 years.

Identifying, defining, and assessing cases of suspected financial abuse have proven difficult. It has therefore often hampered criminal and civil remedies. Several issues are important in this regard. What constitutes abuse, and what are the essential elements of it? How can it be evaluated beyond its legal definition? How can physicians and other healthcare providers help detect and prevent it? In the recent proceedings of The Panel to Review Risk Factors and Prevalence of Elder Abuse and Neglect, ${ }^{7}$ the current state of research on financial abuse was reviewed and the conclusion reached that such abuse has been poorly defined and lacking in validated assessment procedures. It was argued that one of the most important research needs was to create reliable elements of such abuse. Also important is that legal definitions of such abuse may lag clinical understanding of such abuse. Legal definitions may not yet reflect the best knowledge available. Geriatricians, social workers, psychologists, and psychiatrists often are in positions to help prevent or detect financial abuse if they know what to look for. Improved assessment methods may be helpful in bridging the gap between clinical understanding and legal requirements. This is an area in which geriatricians and other experts in geriatrics can be helpful. Because financial abuse is a complex dynamic between two people, involving clinical and financial aspects, ultimate assessment requires professionals to work together and to evaluate different parts of the situation.

Development of a valid and reliable framework for assessing cases of suspected elder financial abuse would therefore be helpful. However, what is the criterion standard to create such a framework? In physical science, direct empirical observation can be used, such as in defining Alzheimer's disease by counting tangles and plaque, but in psychosocial realms, other methodologies must be used. Here, expert opinion may serve as a reasonable start. When there are limited data but a lot of experience (such as in elder financial abuse), it is possible to quantify that knowledge and create a framework until more data are developed that lead to empirically based consensus statements. For example, elements for the assessment and management of Alzheimer's disease were recently developed using an expert opinion approach..$^{8,9}$

The elements of a framework can be discerned in part from the existing literature and in part from the suggestions of practitioners in the field. A framework has been outlined that includes two elements: the presence of a vulnerable older person and an exploitive relationship between the perpetrator and the vulnerable older person. ${ }^{2}$ In developing this framework, a number of cases of elder abuse were reviewed, and the need to examine a variety of causes of vulnerability, not just cognitive impairment, was emphasized. Other causes were disability, depression, and social isolation. It argued that the perpetrator tries to exploit the older person's vulnerability and exert undue influence through a variety of means, including deception, misinformation, withholding information, taking advantage of memory deficits, and taking advantage of trust between the two. Although the framework perceptively described many cases, no empirical data were presented to test this or other models. It has been pointed out that there is always (by definition) misappropriation of assets but also that the "irrational trust" that is often present between the victim and the perpetrator becomes a basis for being able to unduly influence the older person. ${ }^{3}$

In elder financial abuse, some important experts are the professionals who identify, investigate, prosecute, and care for the victims of elder financial abuse: police detectives, district attorneys, Adult Protection Service (APS) workers, victim advocates, and public guardians. By capturing their expertise and combining it with geriatric expertise, cases of such abuse can be better evaluated.

The purpose of this article is to present data on the reliability and validity of a framework for helping to evaluate the presence of elder financial abuse.

\section{METHODS}

\section{Construction of a Framework}

Several steps were used to develop a set of elements that constituted the framework. First, the literature on financial abuse was reviewed to gain a view from experts in the field. This literature suggested a number of elements in the process of abuse: the presence of a vulnerable elder (a person with a medical, psychiatric, or social problem that others might take advantage of) and an exploitive perpetrator. ${ }^{2}$ There are also the actions of the perpetrator to be considered. These are typically manipulative, secretive, and exploitive of a trusting relationship, leading to a loss of assets. ${ }^{3}$ The second source was experience of the Elder Abuse Forensic Center at the University of California at Irvine College of Medicine/County of Orange that indicated that there was usually something missing in cases of financial abuse: an evaluation of the older person by a qualified expert in geriatrics. Typically, the physical and mental health status of the older victim is not well known to investigators until a thorough evaluation can be conducted.

Based upon this literature review and the authors' experience, a list of six proposed elements was created and submitted to 10 professionals experienced in elder financial abuse cases (two deputy district attorneys, two private attorneys, and six APS workers) who were asked to add or subtract items or to change the wording. This panel suggested two new elements, resulting in a set of eight elements. These were combined into a set of four positive and four negative elements. These items were then used in 20 new cases of probable financial abuse that came to the Forensic Center. Four Adult Protective Service workers and a deputy district attorney rated the degree to which each element was present/absent (depending on whether the element was a positive one or a negative one). This analysis indicated that all the elements were considered important and present. This resulted in the following eight elements.

1. An older adult who possesses assets is vulnerable to financial abuse and undue influence from others because of any of a variety of medical, pharmacological, psychological, or social problems.

2. Another person, one who the older person typically trusts, takes advantage of that vulnerability through any of a variety of deceptive actions. These actions constitute the undue influence or the exploitation. The perpetrator 
may have a long-term relationship with the older person, or it may be a new relationship. The trust may have been established through a personal relationship, by a supposed professional position, or because the older person lacked alternatives. The undue influence may be manifested by deceit, creating dependency, intimidation, becoming overly involved in the older person's life or in other ways that take advantage of any vulnerability.

3. Assets, either currently negotiable (e.g., cash) or of future value (e.g., trusts) are transferred from the older person to the perpetrator. The transfers are made during the period of vulnerability.

4. The older person or the transactions are kept isolated, controlled, or secret.

5. A qualified expert did not conduct an appropriate assessment of the older person's capacities and vulnerabilities before the transfer of assets to determine whether it was in the best interest of the older person and whether the older person was acting with sufficient mental capacity, self-determination, and in the absence of undue influence.

6. If assets are transferred, the benefits to the older person are not proportional to the value of the assets transferred to the perpetrator, or the transfer is not consistent with the older person's prior beliefs, wishes, or behavior.

7. Common business or personal ethics are not followed. No agreements are made in writing, there is not full disclosure of the nature of the transaction, there is no right to change one's mind, there is no verification that the older person fully understood the arrangement, or there are conflicts of interest.

8. The alleged perpetrator does not give consideration to the effect of the transaction on others, including the victim, other family members, beneficiaries, or the public welfare system.

The sample of experts then rated the items.

\section{Sample}

A sample of 164 professionals with extensive experience in elder financial abuse was recruited at two advanced training conferences in California that addressed various forms of elder abuse. The original sample consisted of deputy district attorneys, senior law enforcement detectives, APS and related workers (social workers and nurses). The sample was reduced by five people who had less than 3 years experience in financial elder abuse or who had seen fewer than five cases of such abuse. The remaining sample of deputy district attorneys $(n=44)$ had an average of 12.4 years experience and reported that they had prosecuted an average of 20.9 cases, the law enforcement detectives $(n=59)$ had an average of 13.3 years experience with an average of 16.1 cases, and the APS/other workers $(\mathrm{n}=56)$ had an average of 11.3 years experience with an average of 20.1 cases. The final sample of 159 people had a combined total of 1,985 years experience $($ mean $=13.1)$ in elder financial abuse covering 3,225 cases $($ mean $=21.2)$.

\section{Procedure}

A lecture on financial abuse including the proposed framework was presented during the two advanced training con- ferences by one of the authors (BK). The proposed framework for evaluating financial abuse cases was presented, along with its background. After the presentation, the audience was asked to rate how well they thought the framework matched their experience with such cases. They were asked to consider only cases they had previously worked on and that they strongly or certainly believed constituted a case of elder financial abuse and to exclude questionable cases. The questionnaires given to the audience were anonymous and were not a requirement of the course. The university institutional review board gave the research exempt status; consent was not required. The participants were asked to rate the framework as a whole on a five-point scale $(1=$ not at all, $2=$ a little, $3=$ mostly, $4=$ very much, $5=$ almost entirely). Written comments were solicited about individual elements and whether any should be added to or subtracted from the list. Fifty-three percent of the attendees in the first conference returned the questionnaire and $51 \%$ in the second conference.

\section{Data Analyses}

The ratings were summarized for each of the five rating categories. Additional analyses were used to compare the rating across professions, by the number of years in that profession and by the number of cases seen. The relationships between variables were assessed using chi-square $\left(\chi^{2}\right)$ analysis. The validity of the ratings was computed by determining the number of high ratings (very much or almost entirely) in the sample. Reliability was computed by calculating the intraclass coefficient (SAS Institute, Inc., Cary, NC) across raters by randomly dividing the total sample in half and correlating the two subsamples (because the results showed that there were no significant differences between any of the three groups). Even though the range of ratings was restricted; this statistic gives a reasonable estimate of reliability.

\section{RESULTS}

The number and percentage of each profession rating the framework on the five possible rating categories are presented in Table 1 . Ninety percent of the sample stated that the framework of elements captured their experience with financial abuse cases very much or almost entirely, $8 \%$ mostly, about $2 \%$ somewhat, and $0 \%$ not at all. No statistical differences existed on the ratings between professional groups $\left(\chi^{2}=2.1\right.$, degrees of freedom $(d f)=8, P>$ .95 ), number of years' experience (dividing years of experience at the median) $\left(\chi^{2}=1.8, d f=4, P>.80\right)$ or number of cases (also divided at the median) $\left(\chi^{2}=1.7, d f=4\right.$, $P>.80)$. The intraclass correlation coefficient was 0.85 .

\section{DISCUSSION}

\section{Validity and Reliability}

If the experience of this sample of experts can be taken as a reasonable criterion for judging the framework of elements, then it appears to have high validity. Of the sample, $90 \%$ reported that the model very much or almost entirely captured their experience in managing elder financial abuse. The experience of these professionals may be a better criterion than examining only successfully prosecuted cases because the vagaries of prosecution prevent many known 
Table 1. Ratings of Framework by Experts

Rating

\begin{tabular}{ccccc}
\hline Not at All & A Little & Somewhat & Very Much & Almost Entirely \\
\hline \multicolumn{5}{c}{$\mathrm{n}(\%)$} \\
- & $2(3)$ & $7(12)$ & $20(46)$ & $22(50)$ \\
- & $2(44)$ & $24(43)$ & $24(41)$ \\
- & $4(2)$ & $12(8)$ & $70(44)$ & $73(48)$ \\
\hline
\end{tabular}

cases of financial abuse from being prosecuted and because even "guilty" perpetrators may not have been successfully tried, and many cases are settled before trial. It is also a better group than experts in geriatrics because the latter generally lack knowledge of all elements in financial abuse.

There was also high reliability in the ratings within professions and across professions. No significant differences were found across the different professions, and there was high consistency. The reliability index was 0.85 , which is high. Low reliability would have resulted in a wide variation of ratings within a profession or a wide variation in ratings across professions with little interjudge consistency. It therefore seems reasonable to conclude that this framework is valid and reliable as a whole.

\section{Limits}

There are also limits to what these results indicate. First, because of time constraints, the participants did not rate individual items. It is not known whether they thought some of the items were more important than others. This will require subsequent research, but comments by the participants indicated that they thought that the elements were largely complete. Only 17 participants $(11 \%)$ made any comments about adding or subtracting information, and of these, five suggested simply a change of wording. Most of the other suggestions were for consideration of cultural issues, clarification of the term "undue influence," and a description of how much the older person must understand a transaction. Two people who rated the framework in the somewhat category simply said it did not match their experience but did not say why.

Additionally, the sample came entirely from three westcoast states and may not represent the U.S. population of district attorneys, law enforcement officers, and APS workers. This issue will be the subject of subsequent research.

\section{Use of Framework}

The primary use of this framework is to help evaluate cases of suspected elder financial abuse. A team approach will usually be needed, with geriatric specialists evaluating the presence of vulnerable states and the dynamic between the victim and perpetrator and others investigating the change in assets and an examination of documents.

One practical approach in using this framework and these elements in assessing cases of suspected elder financial abuse is to create a chronological timeline that lists the dates of various financial transactions and the corresponding sta- tus of the victim/older person at that time. At some point, the nature of the transactions and the corresponding status of the victim will show a change. The transactions may show an increase in withdrawals from the bank or a change in a trust document. Those transactions will occur, in cases of abuse, when the person is vulnerable. The actions of the perpetrator can also be put on the timeline, such as what statements they made, actions they took, or actions they did not take. A picture of the evolving abuse will typically appear.

\section{Use of Geriatricians and Other Healthcare Experts}

Clinicians can use this information in at least two ways. First, they can be aware that older people are frequently financially abused. Brief screening for it in vulnerable patients should be performed by asking about any recent changes in their finances and whether anyone is asking them to change investments or trusts or to improve their homes. Particularly vulnerable older people are those with diminished cognitive capacity, grief or depression, severe disability, or social isolation. If the clinician is sufficiently concerned, he or she should ask a social worker to look into it further or refer to APS.

Second, clinicians may be called on to provide expert evaluations and opinions for law enforcement, civil investigations, or criminal prosecution about the vulnerability of the older person. Issues such as how much capacity the older person has or had, the degree of dependence on other people who could take advantage of them, and the presence of mental health problems that impair judgment are common issues. Although the typical clinician may not be called on to do a full evaluation of all the elements presented here, they may be called on to evaluate parts of it. Assessment of the dynamics between the victim and perpetrator needs an in-depth interview to determine why the elder trusted or believed the perpetrator, what the victim was hoping to achieve, what the perpetrator did to take advantage of the relationship, and the consequences on the older person.

Using this framework to gather assessment data from suspected victims of abuse requires clinicians who are experts in geriatrics, including psychiatrists, psychologists, and geriatricians. The cognitive, mental health, functional, medical, and neurological issues involved in geriatrics are complex and require an appropriate level of expertise to assess and evaluate, especially in the context of abuse and the legal standards that must be met. The experience of the Elder Abuse Forensic Center indicates that having a geriatrician or geropsychologist perform these evaluations has 
proven highly valuable when coupled with the APS and law enforcement investigation efforts.

In summary, it is possible to empirically develop a framework of elements of financial abuse that may lead to better evaluation of abuse and the possible establishment of agreed-upon guidelines as more data are available. The results of this study are a step in that direction. Future research should focus on cross-validating these elements in a new sample of similar experts, determining whether the elements help investigators and prosecutors to evaluate and try cases, and determining the value of using this model of elder financial abuse as a teaching tool for medical residents, fellows, and other students.

\section{REFERENCES}

1. Hanningan K, Cyphers G, Aravanis S et al. National Center on Elder Abuse (Final Report). Washington, DC: American Public Human Services Association, 1998.
2. Wilber KH, Reynolds SL. Introducing a framework for defining financial abuse of the elderly. J Elder Abuse Neglect 1996;8:61-80.

3. Tueth MJ. Exposing financial exploitation of impaired elderly persons. Am J Geriatr Psychiatry 2000;8:104-111.

4. Myers GC. Demography of aging. In: Binstock RH, George LK, eds. Handbook of Aging and the Social Sciences, 3rd Ed. San Diego: Academic Press, Inc., 1990, pp 19-41.

5. Smeeding TM. Economic status of the elderly. In: Binstock RH, George LK, eds. Handbook of Aging and the Social Sciences, 3rd Ed. San Diego: Academic Press, Inc., 1990, pp 362-380.

6. Kane RL, Ouslander JG, Abrass IB. Essentials of Clinical Geriatrics, 5th Ed. New York: McGraw-Hill, 2004.

7. Hafemeister TL. Financial abuse of the elderly in domestic settings. In: Bonnie RJ, Wallace RB, eds. Elder Mistreatment. Abuse, Neglect, and Exploitation in an Aging America. Washington, DC: The National Academies Press, 2003, pp $382-445$.

8. Cummings JL, Frank JC, Cherry D et al. Guidelines for managing Alzheimer's disease: Part I. Assessment. Am Fam Physician 2002;65:2263-2272.

9. Cummings JL, Frank JC, Cherry D et al. Guidelines for managing Alzheimer's disease: Part II. Treatment. Am Fam Physician 2002;65: $2525-2534$. 